\title{
Ukrainian MOOC: Quantitative and Thematic Analysis of Online Courses
}

\author{
Sergii Sharov ${ }^{\mathrm{a}, *}$, Anatolii Zemlianskyi ${ }^{\mathrm{b}}$, Tetiana Sharova ${ }^{\mathrm{c}}$, Hapotii Viktor ${ }^{\mathrm{d}}$ \\ ${ }^{a}$ Department of Computer Sciences, Dmytro Motornyi Tavria State Agrotechnological University, Melitopol, 72312, Ukraine \\ ${ }^{b}$ Department of Philosophy, Bogdan Khmelnitsky Melitopol State Pedagogical University, Melitopol, 72312, Ukraine \\ ${ }^{c}$ Department of Social Sciences and Humanities, Dmytro Motornyi Tavria State Agrotechnological University, Melitopol, 72312, Ukraine \\ ${ }^{d}$ Department of Law, Bogdan Khmelnitsky Melitopol State Pedagogical University, Melitopol, 72312, Ukraine
}

Corresponding author: *segsharov@gmail.com

\begin{abstract}
The article is devoted to the quantitative analysis of the courses hosted on Ukrainian mass open online courses (MOOC) platforms. It has been found that MOOC, being an effective mechanism of lifelong learning, provides the development of general and professional competencies; it supports principles of openness and accessibility. We have analyzed the online courses located on such well-known Ukrainian online platforms as Prometheus, EdEra, and the Open University of Maidan. It has been found that Ukrainian online platforms started to provide their services not so long ago; they have been working since 2014. Most of the online courses (55.3\% of their total number) can be found on the Prometheus platform. We have also analyzed the dynamics of online course development over the years on each Ukrainian online platform. The average number of advanced online courses on each platform and on all the platforms, in general, has been revealed. The years 2017 and 2019 turned out to be the most productive in the development of courses. The analysis of thematic areas of the developed online courses has been carried out; the identical sections available on each considered platform have been revealed. The largest number of courses is presented among such sections as Education/EIE (External Independent Evaluation) and Law, proving their relevance among users. The largest number of thematic areas is presented on the Prometheus platform. It has been found that Ukrainian MOOCs have a significant difference in the number of courses compared to a number of well-known foreign online platforms.
\end{abstract}

Keywords - MOOC; online courses; Prometheus; EdEra; OUM.

Manuscript received 13 Nov. 2020; revised 12 Jan. 2021; accepted 2 Feb. 2021. Date of publication 30 Jun. 2021. IJASEIT is licensed under a Creative Commons Attribution-Share Alike 4.0 International License.

\section{INTRODUCTION}

Modern trends in the labor market are characterized by increasing competitive requirements for the specialist. Since many educational processes take place in the information sphere in the conditions of rapid aging, there is a need for constant updating (not accumulating!) of knowledge and professional and general competencies development. The higher education system solves most of the tasks related to the training, development, and self-development of the future specialist in students' educational activities.

Nowadays, enlarging higher schools through mergers with other educational institutions is being observed in Ukraine. The remaining schools are trying to become more efficient and competitive. This goal is achieved through various activities, including branding of higher education institutions among potential entrants [1], the use of information and communication technologies (ICT) for the organization of management and educational processes, and improving educational content quality and others.

The spread of ICT throughout the population and students, the implementation of remote communication, and the Internet in educational activities have significantly affected higher education institutions' functionality and organization. Within the competence and student-centered approaches, the student is a central figure in the educational space, which should fully reveal its potential in educational activities. Employing ICT use, the individualization of learning is provided, and the creation of new approaches to teaching, objective assessment of student achievements, it occurs the implementation of the educational paradigm, which aims to develop the necessary information [2], professional and general competencies, etc.

Along with the traditional forms of education, usually of attending classes in an educational institution, there are many distance educations forms. Among them, various webinars, 
online seminars, master classes, online courses and such should be noted. Online events can be held systematically or periodically, be initiated by an educational institution or other institution, be a separate educational component, or a part of a training course. Such diversity and popularity of online education come from the significant increase in demand for lifelong learning, advantages of the learning process individualization [3], the need to reduce social inequality in education, the need for free access to educational content [4].

Today, we observe significant attention to Ukrainian MOOCs due to the global pandemic [5] and the understanding of the powerful opportunities and prospects of online education [6]. In particular distance learning courses, various forms of online education allow to create of a single educational environment in the digital space and provide free access for many users to the required information. As a result, through MOOC and distance learning, users will develop their competencies and become more employable.

The most famous Ukrainian MOOC platforms are Prometheus, EdEra, and the Open University of Maidan (OUM). The goal of the Prometheus platform is to create online courses for everyone on a cost-free basis. Through cooperation with the best educational institutions and international organizations, Prometheus ensures the effective implementation of blended learning and strives to make a "revolution in education" and helps everyone "change their lives" for the better. The online platform cooperates actively with international organizations, such as IREX Ukraine, British Council, USAID, and others.

The purpose of the educational project EdEra is to introduce innovative educational solutions in the traditional educational process, the organization of quality national education. EdEra online education studio develops online courses and interactive textbooks based on an individualized approach to students. EdEra's main areas of activity are school, vocational, civic, and corporate education. The online platform cooperates actively with Ukraine and international organizations (Ministry of Education and Science of Ukraine, IREX Ukraine, VOX Ukraine, etc.).

The goal of the OUM online platform is to provide civic education through non-formal online education. The platform belongs to the public organization with the same name, which promotes the expression of an active public position by every inhabitant of the country, forming civic competencies. The public organization cooperates with various international organizations, in particular UNDP Ukraine, to ensure sustainable development of the state. As Ukrainian online platforms contain the most quality educational content in Ukrainian, they are often used by Ukrainian citizens to improve their competencies. Therefore, there is a need for quantitative analysis of online courses located on Ukrainian online platforms and their thematic focus.

\section{MATERIAL AND METHOD}

\section{A. LMS vs MOOC}

Nowadays, the most common e-learning tools are mass open online courses (MOOC) and Learning Management System (LMS). Both systems provide remote access to educational material e training specialists [7], contributing to the formation of the student's individual academic trajectory, developing informative competencies, ability to independence, self-motivation, and having similar control and feedback means. Educational motivation to acquire knowledge, own career goals, developed informative competencies [8], the necessary technical equipment, Internet access are imperative in completing the courses.

At the same time, MOOCs have some differences with LMS, distinguishing them one from another. Typically, distance learning systems provide authorized access to information for higher education students only. They include educational content that corresponds to the current work programs of particular specialties [9]. On the contrary, MOOC is available to anyone, just register for an online course. There is a significant difference in the number of users. Much more users can enroll in the MOOC online course [10] than for a course located in the distance learning system. Bali [11] rightly points out that MOOCs' openness and scalability raise certain issues but provide unprecedented opportunities for teaching and learning.

There is a difference between MOOC and LMS regarding the commercialization of educational activities and the promotion of higher education institutions [6]. Students use the distance learning system and the courses located there within the academic environment of the educational institution. Teachers of the educational institution create educational content. It is free for students. Online courses on MOOC platforms are created and completed by teachers and developers from different academic institutions and organizations of other forms of property. They can be free or provide a certain fee for passing, certificate, etc.

\section{B. Problems of Use of MOOC}

On several occasions, research has raised problems on the importance of mass open online courses to modernize higher education and change educational paradigms. As a result, there are two opposing views on their usefulness and effectiveness. On the one hand, MOOCs are associated with an effective mechanism for the organization of lifelong learning [12], the destruction of the outdated education system, and its transformation into online education. Despite optimistic forecasts regarding the implementation of online education through MOOCs, they have certain shortcomings that need to be addressed. These include the insufficient number of tasks aimed at the development of abilities and skills, the inability to identify the student during the implementation of control measures, partial violation of the academic integrity principles (cheating) [3], low quality of some online courses, and their increase only exacerbates this problem [13].

As a result, some users do not reach the end of the online course or leave the course after registration immediately [14]. In addition to objective reasons, this situation may be related to the human factor:

- random choice of course for fun, lack of basic knowledge about the chosen course [8];

- users do not possess sufficiently developed abilities to use MOOC tools, the Internet, and other information services [2].

- low motivation to study the course [15], the insufficient interest of educational institutions in the use of online educational modules [16]. 
- lack of technical capacity to provide sustained Internet connection [17].

- lack of live communication with peers and teachers, non-compliance with time limits during the course [18].

- insufficient financial capacity to take paid online courses, language barrier, etc.

The quality of educational content plays an important role in creating and using online courses, which reputable scholars and educators have repeatedly pointed out. The topics of the created course should be relevant [8], and educational content - interesting and structured. Often an interesting course contains a poor-quality video where the lecturer does know the information well or dictates the training material. Of course, such courses will not attract users and will not be completed. Therefore, course developers should be aware of the methodology of MOOC applications, possible issues, and ways to solve them [11].

\section{Methodology}

The study is based on statistics on the online course number located on three Ukrainian-language MOOC platforms (Prometheus, EdEra, OUM). It is not about getting a certificate after passing, but generally about online courses that can be taken at any time without paying for the educational service provided. As of May 2020, 235 courses were available on the online platforms noted above. The study covered all online courses developed at that time: Prometheus - 130 courses, EdEra - 49 courses, OUM - 56 courses.

The choice of these platforms was based on their popularity among higher education seekers, teachers, preliminary analysis, and generalization of research and Internet sources. My own practical experience also influenced the choice. The authors have a significant number of certificates of successful completion of courses located on each of the considered Ukrainian-language online platforms.

According to predetermined features, the method of classification has been used to determine the thematic areas of the developed online courses. The thematic areas listed on the platforms in the sections "Course Cycles" (Prometheus), "Course Rubricator" (OUM) were chosen as a feature for

classification. For the online platform EdEra, the thematic areas were determined based on logical inference and the course content analysis independently.

Quantitative analysis methods were used to determine the number of courses by year, to determine the relative share of courses in a particular subject area in the total number of courses on a particular platform or all platforms in general. The methods of comparative analysis were used to determine the online platforms on which most online courses are located, the number of studies on a specific topic, etc. The number of developed online courses on each online platform as a percentage, depending on the total number of developed courses, was calculated by the formula:

$$
S_{i}=\frac{P_{i}}{\sum_{i=1}^{i=3} P_{i}} * 100 \%
$$

Where:

$P i$ - the total number of courses on the online platform $i$;

$i$ - number of the online platform.

For calculations, we assume that $P 1$ - Prometheus; $P 2$ EdEra; P3 - OUM.

\section{RESULTS AND DISCUSSION}

Ukrainian MOOC platforms began their existence and dissemination in 2014 when in the world of online education, well-known platforms have been presenting their courses to a wide audience of users for 2 years. On the Prometheus platform, two courses were created, entitled "Financial Management" (beginning of the course on November 12, 2014) and "Modern History of Ukraine: from the beginning of the Second World War to the present" (beginning of the course on November 19,2014). This choice was quite logical because financial literacy and the country's history are relevant thematic areas. Later, other online platforms began to present their work. Including the online platform EdEra, which started operating in 2015, and the online civic education platform OUM, which posted the first online course in 2016 (Tabl. 1).

TABLE I

NUMBER OF CREATED ONLINE COURSES ON UKRAINIAN MOOC PLATFORMS BY YEARS

\begin{tabular}{llllllllll}
\hline \multirow{2}{*}{ Online platforms } & \multirow{8}{*}{ Count of courses } & \multicolumn{10}{c}{ Years } \\
\cline { 3 - 10 } & & $\mathbf{2 0 1 4}$ & $\mathbf{2 0 1 5}$ & $\mathbf{2 0 1 6}$ & $\mathbf{2 0 1 7}$ & $\mathbf{2 0 1 8}$ & $\mathbf{2 0 1 9}$ & $\mathbf{2 0 2 0}$ & Dateless \\
\hline Prometheus & 130 & 2 & 14 & 14 & 28 & 21 & 27 & 24 & - \\
EdEra & 49 & - & 7 & - & 7 & 8 & 12 & 9 & 6 \\
OUM & 56 & - & - & 19 & 16 & 9 & 9 & 3 & - \\
Bсbого & 235 & $\mathbf{2}$ & $\mathbf{2 1}$ & $\mathbf{3 3}$ & $\mathbf{5 1}$ & $\mathbf{3 8}$ & $\mathbf{4 8}$ & $\mathbf{3 6}$ & $\mathbf{6}$ \\
\hline
\end{tabular}

On average, about 29 online courses are created annually on all three platforms. Most online courses were created in 2017 (51 online courses). At that time, 28 online courses were developed on the Prometheus platform, 7 courses on the EdEra platform, and 16 online courses on the OUM platform. The second place by the number of created online courses in 2019, during which 48 online courses were created. 27 online courses were developed on the Prometheus platform, 12 courses on the EdEra platform, and 9 online courses on the OUM platform. It should be noted that 6 online courses $(2.6 \%$ of the total) do not contain the date of creation, so it is impossible to determine a specific period they belong to.

Analyzing the dynamics of the creation of courses on each platform over the years, the following conclusions can be drawn. For the whole period on the Prometheus platform, an average of 16 online courses is created per year, on the EdEra platform - 5 online courses, on the OUM platform - 7 courses. On the Prometheus platform, since 2017, an average of 25 courses are created annually. On the EdEra platform, since 2017, an average of 9 courses are created annually. On the OUM platform, the dynamic creation of online courses started 
in 2016 (19 courses) with a gradual reduction of this figure to 9 online courses per year (Fig. 1).

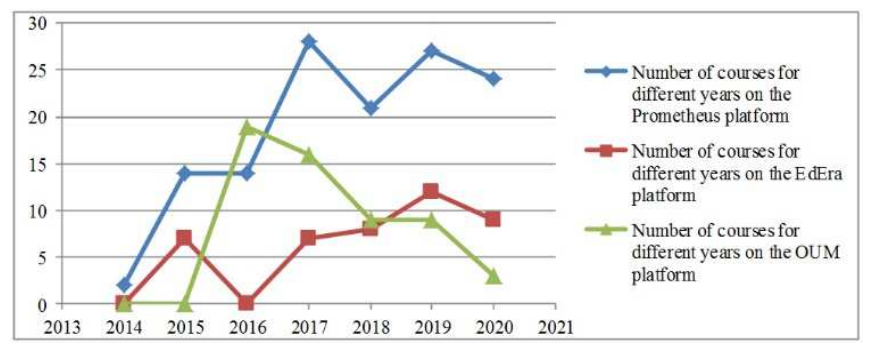

Fig. 1 Dynamics of online course development on Ukrainian MOOC platforms

The decrease in the number of online courses developed on the OUM platform can be explained by its specifics aimed at civic education mostly. However, this does not mean that the specific focus of the online platform OUM will limit its further development. At the same time, courses on various topics are available on other Ukrainian platforms. Observing the dynamics of online courses and the popularity of online education, we expect in 2020 the number of developed online courses on all three platforms at 45-50.

Analysis of the total number of courses on each of the platforms revealed that the Prometheus platform provides the most opportunities for lifelong self-education. It presents the most sections and houses more than half of all Ukrainianlanguage online courses (Fig. 2).



Fig. 2 The number of developed online courses in Ukraine as a percentage

In the virtual educational space of Ukraine, there are more than ten thematic areas in which online courses are created on Ukrainian-language platforms (Table 2). The presented topics of the online courses can be grouped as follows: Law, Advanced Training / Education / External Examination, Media / Journalism, Economics / Philosophy / Management, Health, Civic Education, Thinking, Community, Information Security / Programming, Social Work, History, English, Communication. This variety reflects a wide spread of online education in the training areas of future specialists and working professionals. In turn, the authors are grateful to the variety, cost-free, and availability of a certificate after taking an online course; it is possible to promote Ukrainian MOOCs among the population.
TABLE II

THEMATIC DIRECTIONS OF ONLINE COURSES ON UKRAINIAN MOOC PLATFORMS

\begin{tabular}{lllll}
\hline \multicolumn{1}{c}{$\begin{array}{c}\text { Thematic } \\
\text { direction }\end{array}$} & Prometheus & EdEra & OUM & Total \\
\hline Law & 18 & 11 & 9 & 38 \\
Certification & 4 & 11 & 2 & 17 \\
training & & & & \\
Education / EIT & 25 & 15 & 4 & 44 \\
Media / & 9 & 4 & 1 & 14 \\
Journalism & & & & \\
Economics / & 14 & 3 & 6 & 23 \\
Philosophy & & & & \\
Health & 10 & 4 & 3 & 17 \\
Administration & - & 1 & - & 1 \\
Marketing / & - & - & 8 & 8 \\
Management & & & & \\
Civil education & 18 & - & - & 18 \\
Thinking & - & - & 10 & 10 \\
Community & - & - & 8 & 8 \\
Inform. security & - & - & 5 & 5 \\
Programming & 11 & - & - & 11 \\
Social work & 3 & - & - & 3 \\
History & 4 & - & - & 4 \\
English & 6 & - & - & 6 \\
Communication & 8 & - & - & 8 \\
Total & 130 & 49 & 56 & 235 \\
\hline
\end{tabular}

Talking about the relevance of thematic sections on each of the platforms, the most relevant thematic area on the Prometheus platform is Advanced Training / Education / EIT (29 online courses), which makes up $22.3 \%$ of the total number of courses on this platform. The areas of Law and Civic Education turned out to be not less common. According to these thematic areas, 18 courses have been created, which is $13.8 \%$ of the total number of online courses on the Prometheus platform.

On the EdEra online platform, the most common topics were Advanced Training/Education / EIT, within which 26 courses have been developed. This is $53 \%$ of the total number of online courses on the platform. The Law area turned out to be not less common (11 online courses / 22.4\%).

On the OUM online platform, the most common topics were Economics / Management / Administration / Philosophy (14 online courses, which is $25 \%$ of the total number on the platform) and Thinking (10 courses / 17.9\%). Also popular on this platform are the Community ( 8 courses / 14.2\%), Law (9 courses / 16\%) and Information Security (5 courses / 8.9\%). The popularity of these topics is due to the specifics of this online platform and its purpose - to provide civic education and education for communities.

While analyzing the thematic areas of the developed online courses on all three platforms, the most common headings are Advanced training / Education/EIT (61 online courses or 25.9\% of the total number of courses), Law (38 courses/16.2\%), Economics/ Management/Administration/ Philosophy (31 online courses $/ 13.2 \%$ ). In our opinion, these headings indicate the prevalence of educational trends that are relevant for teachers, lecturers, students, and pupils. Besides, professions related to IT, economics, and law are traditionally relevant.

The analysis of thematic areas on different online platforms revealed six identical headings: Law, Advanced Training, 
Education / EIT, Media / Journalism, Economics / Philosophy, Health (Fig. 3).

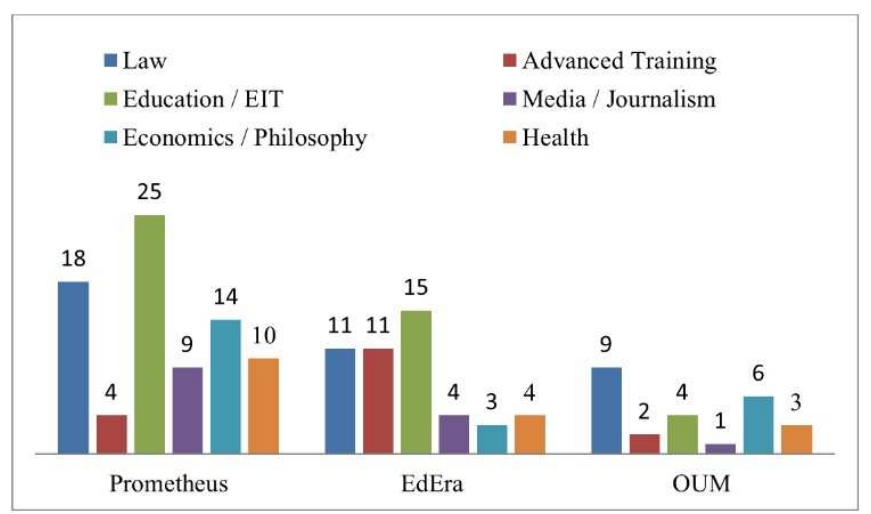

Fig. 3 Number of online courses in the same thematic area

Only those courses that are fully accessible to users and do not require payment were taken for analysis. 153 online courses were developed in these thematic areas, which is $65.1 \%$ of the total number of developed courses. Among the six presented thematic rubrics, the rubrics Education / EIT and Law dominate, which contain 44 (18.7\% of the total number of courses) and 38 (16.2\% of the total number of courses) courses.

While analyzing, thematic sections presented on two platforms have been identified. For example, the Marketing / Management / Administration section presented at EdEra and OUM contains 9 online courses, which is $3.8 \%$ of the total number of courses. This division into thematic sections is notional and may be supplemented over time, as Ukrainian MOOCs are updated with new courses constantly.

It should be noted that there is a significant difference in the number of courses available on Ukrainian-language online platforms and well-known foreign MOOCs. For example, in 2020 , there are more than 4,300 online courses on the Coursera online platform and more than 2,500 on the Edx platform. Filter courses by "free" or "free courses" gave the following quantitative results: Coursera -1600 , Edx - 696 online courses. At the same time, the three considered platforms, which are the main ones in the educational space of Ukraine, contain only 235 online courses.

Perhaps this difference is due to the creation time of wellknown online platforms (all platforms were created in 2012), which had the opportunity to accumulate online courses on various topics. On the contrary, courses on Ukrainianlanguage platforms have appeared quite recently (Prometheus - 2014, EdEra - 2015, OUM - 2016). This testifies to their youth and further prospects for the creation and filling of courses. At the same time, Ukrainian-language platforms try to create their educational content [19]. Leading teachers of domestic educational institutions often develop it in cooperation with international organizations. In addition, if earlier online courses were designed mainly for active, working people over 26 [4] and students [20], now there are online courses for teachers, managers, the younger generation, and others.

We support the scientists' opinion considering MOOCs one of the means of popularizing educational institutions. When teachers create an online course, they indirectly advertise the educational institution among potential students [3]. On the other hand, many users choosing an online course focus on its subject and developer. If the developer is a leader among educational institutions, it is assumed that he fills the course with relevant and quality content. However, this situation is not always true [13]. Some online courses are too simple and uninteresting, making no sense to spend time on them.

We consider the following to be promising measures to promote MOOC in Ukraine:

- It is necessary to provide a number of measures aimed at reducing the risk of losing students' cognitive motivation. These may be face-to-face meetings with students to discuss the online course results. Or search for an online course that contains multimedia educational content, not just text and tests.

- Recognize the results of passing the MOOC at the legislative level. Certain developments in this direction are already available. For example, this applies to primary school teachers who need to complete a course located on the EdEra platform for successful employment. For example, this is a mandatory online course for primary school teachers located on the EdEra platform to be successful.

- At the level of higher education institutions, learning on the MOOC platform should be considered an element of non-formal education in the formal education system. Certificates of successful completion of the online course must be taken into account when accumulating points in the relevant discipline [3].

- Development of constructive cooperation between Ukrainian and well-known foreign online platforms, as well as higher education institutions. Interaction between partners should include the development of new online courses, the use of existing ones at the level of non-formal education, grant and information support, joint educational and research activities.

- Motivation of teachers and online courses developers to create quality educational content that will provide the appropriate level of online education [19]. It should be noted that online courses located on Ukrainianlanguage online platforms and created by higher education teachers with the support of international organizations, foundations, and others. This allows teachers to present their knowledge and experience and students to receive the provided information.

- Change the financing policy and support higher education, especially for people with limited financial resources or low social status [14]. At the same time, it is necessary to focus on society's needs in certain areas and students' interests [21].

It should be noted that the technological development of society is a very dynamic process, which adapts to various areas of activity, including education. Moreover, the created technologies, devices, and gadgets are often used to implement specific tasks due to the specifics of the subject area. According to scientists, any educational technology, including MOOC, is likely to be assimilated by a sustainable education system [14]. As a result, it will be modernized to reflect new trends.

Special attention should be paid to the possibility of the simultaneous use of MOOC and LMS in higher education. All of them provide the organization of e-learning and blended 
learning and the acquisition of necessary competencies by students.

My own experience has confirmed the effectiveness of blended learning when an in-depth study of a discipline or special course is achieved through several online courses on related or similar topics. Besides, even equal online courses, located on different platforms, are different in educational content, means of control, etc. Therefore, it is appropriate to use LMS in a higher education institution and, additionally, to use MOOC, which contains online courses on similar topics.

LMS use in higher education allows exchanging academic resources and educational information between teachers and students, providing feedback between them [22], assessing academic achievements, maintaining the control results, generating reports, etc. If you use commercial learning management systems, then there is a problem with a free upgrade and integration with other university systems [23]. In the case free LMS are available, students and teachers use only those tools that are integrated into the system.

Having their autonomy, higher education institutions can implement various LMS in the educational process, such as Google Classroom, Moodle, etc. According to the authors, the criterion for choosing learning systems is the internal policy of the university regarding the organization of the educational process, the availability of agreements with developers, the possibility of free use, recommendations of the Ministry of Education and Science of Ukraine, the availability of prepared training materials for the contract educational platform, etc.

With the help of the tools built into the LMS [24], teachers can create distance courses and fill them with educational content according to the syllabus of the discipline. On the other hand, MOOC online courses contain other educational information that teachers of leading educational institutions develop.

In order to take advantage of MOOC and LMS, it is appropriate to use a modular approach when studying disciplines when separate or additional blocks of learning material are located on MOOC platforms. In this aspect, the study on the use of MOOCs for blended learning of Bruff D. O. et al. is relevant. In this case, separate modules of online courses (video) are introduced into the educational process during the study of relevant disciplines. Researchers emphasize that in this way, it is possible to combine different forms of educational material presentation and ensure the receipt of information from various sources. In this case, functions of the teacher are changed from a source of knowledge to a facilitator [25], who can show the best ways to study the subject. Besides, there is evidence of students' interest in using MOOC via mobile devices in rural areas, where the speed and stability of the Internet do not always meet the needs of users [5].

The choice of online courses for additional study within the discipline is the responsibility of teachers and it partially depends on students. In this case, students' learning motivation and level of satisfaction will increase; they will be focused on the use of electronic educational resources during blended learning [26]. At the same time, the issue of using only one system (MOOC or LMS) to ensure the educational process is debatable and it requires a separate study.

\section{CONCLUSION}

It can be stated that Ukrainian MOOCs have the right to exist. They are filled constantly with new courses on various topics. The most famous Ukrainian MOOCs began their existence in 2014, gradually increasing the number of online courses on their platforms. Quantitative analysis of Ukrainian MOOCs revealed 235 online courses created by March 2020. The Prometheus platform has more than half of the total online courses (130 courses), which indicates the platform's popularity and the variety of topics. The fewest courses are created on the EdEra platform (49 courses). On the Ukrainianlanguage platform OUM emerged later than Prometheus and EdEra, 56 online courses have been created. The largest online courses on all three platforms were created in 2017 (51 courses) and in 2019 (48 courses). A similar number of new courses is expected in 2020 .

The thematic rubrics of Law, Advanced Training, Education / EIT, Media / Journalism, Economics / Philosophy, Health are the same for all three platforms. The number of online courses included in these thematic areas is $65.1 \%$ of the total number of developed online courses. The most popular among the identified identical rubrics are Education / EIT (18.7\% of the total number of courses) and law (16.2\% of the total number of courses).

We consider MOOC a lifelong learning tool that can be used effectively in combination with traditional learning. Under the conditions when blended learning is being introduced in the educational process of higher education institutions, it is appropriate to combine different online platforms. Further research is expected to analyze online course developers. It is assumed that developers are higher education teachers, international and domestic organizations of various forms of ownership, and author teams.

\section{REFERENCES}

[1] O. V. Soroka and M. S. Kryvtsova, "The brand of a higher education institution is the basis of competitiveness in the market of educational services," Scientific Bulletin of Uzhhorod National University. Series: International Economic Relations and the World Economy, vol. 19(3), pp. 65-70, 2018

[2] G. Conole, "MOOCs as disruptive technologies: strategies for enhancing the learner experience and quality of MOOCs," Rev. Educ. a Distancia, no. 50, 2016, doi: 10.6018/red/50/2.

[3] H. Kuzmenko and O. Khorolskyi, "Massive open online courses in the context of transformation of higher education in Ukraine," Pedagogical sciences, vol. 63, pp. 56-61, 2015.

[4] R. De Rosa, "A research agenda on MOOCS: the perspective of social sciences," Italian Journal of Educational Technology, 26(2), 2018, doi: 10.17471/2499-4324/993.

[5] Lytovchenko and H. Voronina, "MOOC as Remote ESP Learning Tool at University in Quarantine: Focus on Students' Attitudes," Rev. Rom. pentru Educ. Multidimens., 2020, doi: 10.18662/rrem/12.2sup1/291.

[6] O. I. Mehedyniuk and N. V. Yudina, "Online education platforms as effective communication channels," Current problems of economics and management, vol. $13 . \quad$ Available: http://ape.fmm.kpi.ua/article/view/166658/166006.

[7] S. Sharov, V. Liapunova, and T. Sharova, "Analysis of the opportunities of the prometheus platform for the professional development of future teachers," TEM J., vol. 8, no. 4, 2019, doi: 10.18421/TEM84-52.

[8] V. Kukharenko, "Designing massive open online courses," in CEUR Workshop Proceedings, 2013, vol. 1000.

[9] Adamova and T. Golovachuk, "Distance learning: a modern view of the advantages and problems," The origins of pedagogical skills. Series: Pedagogical sciences, vol. 10, pp. 3-6, 2012. 
[10] E. Smyrnova-Trybulska, N. Morze, and L. Varchenko-Trotzenko, "MOOCS - selected social and educational aspects," 2015.

[11] M. Bali, "MOOC Pedagogy: Gleaning Good Practice from Existing MOOCs," MERLOT J. Online Learn. Teach., vol. 10, no. 1, 2014.

[12] D. J. Skiba, "Disruption in higher education: Massively open online courses (MOOCs)," Nurs. Educ. Perspect., vol. 33, no. 6, 2012, doi: 10.5480/1536-5026-33.6.416.

[13] Margaryan, M. Bianco, and A. Littlejohn, "Instructional quality of Massive Open Online Courses (MOOCs)," Comput. Educ., vol. 80, 2015, doi: 10.1016/j.compedu.2014.08.005.

[14] J. Reich and J. A. Ruipérez-Valiente, "The MOOC pivot," Science, vol. 363, no. 6423. 2019, doi: 10.1126/science. aav7958.

[15] P. Fidalgo, J. Thormann, O. Kulyk, and J. A. Lencastre, "Students' perceptions on distance education: A multinational study," Int. J. Educ. Technol. High. Educ., vol. 17, no. 1, 2020, doi: 10.1186/s41239-02000194-2.

[16] H. M. Kravtsov, M. O. Vinnyk and Yu. H. Tarasich, "Research of the influence of the quality of electronic educational resources on the quality of educational services with the use of distance learning technologies," Information technology in education, vol. 16, pp. 8394, 2013.

[17] M. Adnan, "Online learning amid the COVID-19 pandemic: Student's perspectives," J. Pedagog. Res., vol. 1, no. 2, 2020, doi: 10.33902/jpsp.2020261309.

[18] D. Gamage, I. Perera, and S. Fernando, "Exploring MOOC user behaviors beyond platforms," Int. J. Emerg. Technol. Learn., vol. 15, no. 8, 2020, doi: 10.3991/IJET.V15I08.12493.
[19] V. L. Osetskyi and I. L. Tatomyr, "The role of massive open online courses in the modern educational landscape," Ukraine economy, vol. 12, pp. 86-98, 2017.

[20] N. Albelbisi, F. D. Yusop, and U. K. M. Salleh, "Mapping the factors influencing success of Massive Open Online Courses (MOOC) in higher education," Eurasia J. Math. Sci. Technol. Educ., 2018, doi: 10.29333/ejmste/91486.

[21] H. Husain, S. B. Thalib, A. Ahmad, and A. Anshar, "Development of analog-based online electronic learning models in improving students learning outcomes in informatics engineering study programs," TEM $J .$, vol. 8, no. 1, 2019, doi: 10.18421/TEM81-39.

[22] B. Bervell and V. Arkorful, "LMS-enabled blended learning utilization in distance tertiary education: establishing the relationships among facilitating conditions, voluntariness of use and use behaviour," Int. J. Educ. Technol. High. Educ., vol. 17, no. 1, 2020, doi: 10.1186/s41239-020-0183-9.

[23] L. Abazi-Bexheti, A. Kadriu, M. Apostolova-Trpkovska, E. Jajaga, and H. Abazi-Alili, "LMS Solution: Evidence of Google Classroom Usage in Higher Education," Bus. Syst. Res., vol. 9, no. 1, 2018, doi: 10.2478/bsrj-2018-0003.

[24] R. Kraleva, M. Sabani, and V. Kralev, "An analysis of some learning management systems," Int. J. Adv. Sci. Eng. Inf. Technol., vol. 9, no. 4, 2019, doi: 10.18517/ijaseit.9.4.9437.

[25] D. O. Bruff, D. H. Fisher, K. E. McEwen, and B. E. Smith, "Wrapping a MOOC: Student Perceptions of an Experiment in Blended Learning," MERLOT J. Online Learn. Teach., 2013.

[26] K. A. Al-Busaidi, "Learners' perspective on critical factors to LMS success in blended learning: An empirical investigation," Commun. Assoc. Inf. Syst., vol. 30, no. 1, 2012, doi: 10.17705/1 cais.03002. 